United States

\section{Inventorship dispute stalls DNA patent application}

\section{Is scientific history being rewritten to make research results more patentable? David Dickson reports}

A PATENT application covering some of the basic techniques of genetic engineering is being held up by the US Patent Office in a dispute over whether the applicants can legally claim to be the sole inventors. The patent request has been filed jointly by Stanford University and the University of California, San Francisco, (UCSF) on behalf of Dr Stanley Cohen and Dr Herbert Boyer. It covers techniques developed at the two institutions in the early 1970s, which demonstrated for the first time the feasibility of replicating biologicallyfunctional foreign genes introduced into a living organism.

Central to the patent application, first filed in 1974, is a paper published in the Proceedings of the National Academy of Sciences $(70,3240,1973)$ in the preceding year, which describes the successful construction and replication of a plasmid capable of transferring antibiotic resistance into Escherichia coli.

In addition to Cohen and Boyer, the paper names two other authors Dr Annie Chang of Stanford and Dr Robert Helling, Associate Professor of Botany at the University of Michigan. According to the rules of the Patent Office, joint authorship means the two are considered co-inventors of the processes described.

Stanford and UCSF argue that although the research described in the paper and the patent application was built on techniques developed elsewhere, it was Cohen and Boyer who provided the creative input necessary to demonstrate their potential. They did this by conceiving and demonstrating how the techniques could be combined to create functional recombinant plasmids.

But Helling, who is not named in the patent application, disputes that his role was marginal. He has refused to sign a disclaimer, required by the Patent Office before it approves the application, agreeing that he was not an inventor of the processes described.

"I felt that we were all equal in this, and do not want to sign a letter saying that I was just another laboratory worker", he told Nature last week. "I was part and parcel of the whole thing; I don't feel that I should sign something that I do not believe is true."

Helling is not the only scientist who has refused to sign (although his refusal has been the most disruptive). Dr John Morrow, of Johns Hopkins University, the first author on a 1974 PNAS paper cited by

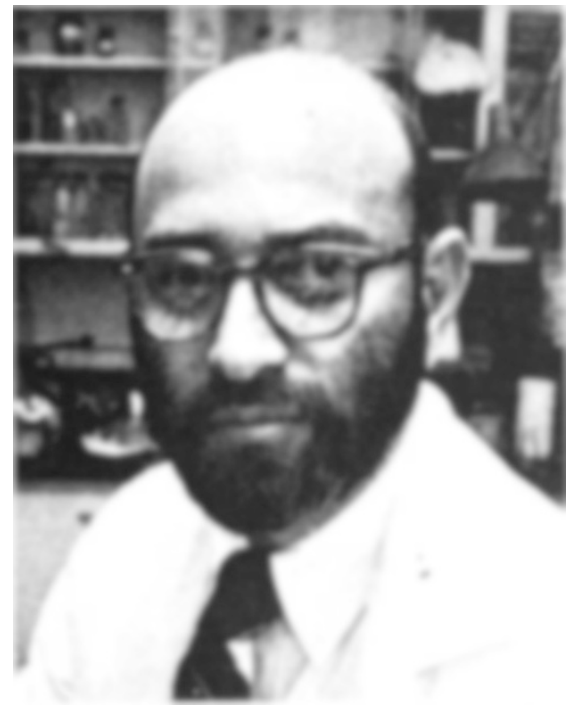

Cohen: forgoing royalties

Cohen and Boyer (to show how a bacterial plasmid could be used to reproduce Xenopus DNA), complains in particular about the secrecy which has covered the application. "I am not prepared to sign a disclaimer to a patent application that I have not seen," he says.

And there may be further disputes in store. In addition to the process patent, Stanford and UCSF are also asking protection for the plasmid developed, arguing that it was the development of this particular pSC101 plasmid that made the success of the techniques possible.

Meanwhile, patents are being granted on the processes used. Dr Roy Curtiss, of the University of Alabama, has recently been granted a patent for the techniques used to create the disabled $\chi 1776$ strain of $E$. coli (for which both process and product patents have already been issued in the UK).

The issue has raised at least two separate arguments. The first is on the morality of granting private licensing rights to the results of research carried out on public funds. As this is currently accepted practice, most scientists feel that Stanford and UCSF are justified in seeking to benefit from research which the two institutions pioneered - particularly since the two universities stress that the patents would remain freely available to anyone who wanted to use the techniques for research purposes. And both Cohen and Boyer have agreed that royalty proceeds should go to support research at the universities, and that neither will benefit directly.

A further difficulty arises from the clash between scientific conventions of coauthorship, and the legal implications of these conventions when it comes to claims of inventorship. The latter is a legal definition which courts have ruled is enshrined in the Constitution, but is seldom considered by scientists in determining whose name should go on a research paper. Patents can be granted for techniques whose details have been published less than a year previously, but where such prior publication has taken place, all those listed as co-authors are treated as prima facie co-inventors.

In the Stanford/UCSF case, all agree that the development of recombinant DNA methodologies relied heavily on discoveries made at several institutions, for example on work on restriction enzymes at Johns Hopkins University and by Paul Berg's group at Stanford, or on the functioning of ligases at the National Institutes of Health.

As Cohen puts it: "Scientific advances such as the one we have been involved in are in fact the result of multiple discoveries carried out by many individuals over a long period of time". The difficulty lies in evaluating the significance of any particular contribution.

Patent attorneys for the two universities argue that Boyer and Cohen provided the "major inspiration and direction" for the experiments described in the PNAS paper, and they have told Helling that, unless he signs the disclaimer - or they can convince the patent examiner by other means that he has no legal claim as an inventor - then they will seek a court order instructing the issuing of a patent, and 'deposing' him as an inventor. But a full-scale legal dispute is not a prospect that anyone fancies.

Legally-defined constraints imposed by commercial considerations are proving a problem for scientists concerned to retain the integrity of the research process.

"It is difficult to demand high standards of your students when you see some of the things that are going on", says Dr Mark Ptashne of Harvard University, who claims that colleagues are beginning to write papers and cite references. "In such a way that their patent applications are valid".

Dr Zsolt Harsanyi, who is currently heading a major study of the implications of recombinant DNA technology for the office of Technology Assessment, confirms that "in the past couple of months" scientists have begun to talk about the potential for rewriting scientific history as a "serious problem".

Some are now using this as an argument against permitting the patenting of research results at all. Others suggest that fields such as electronics and chemistry have faced such conflicts for years, and have learned to live with the consequences.

In the case of molecular biology, the learning process does not look like being a comfortable one. 